\title{
Correction to: Being and Becoming: Emerging Relationalities with Space/Place and Socio-Technical Geographies
}

Lakshmi Priya Rajendran, NezHapi Dellé Odeleye, Ruxandra Kyriazopoulos-Berinde and Maryam Fazel

\section{Correction to:}

Chapter 1 in: L. P. Rajendran and N. D. Odeleye (eds.), Mediated Identities in the Futures of Place: Emerging Practices and Spatial Cultures, Springer Series in Adaptive Environments, https://doi.org/10.1007/978-3-030-06237-8_1

The original version of the book was inadvertently published with omission of co-author's name in chapter 1 , which has now been updated and approved by the editor. The chapter has now been updated with changes.

The name of the co-author is:

Maryan Fazel

Tehran, Iran 